Document downloaded from:

http://hdl.handle.net/10251/145419

This paper must be cited as:

Boscardin, J.; Yepes, V.; Kripka, M. (08-2). Optimization of reinforced concrete building frames with automated grouping of columns. Automation in Construction. 104:331-340. https://doi.org/10.1016/j.autcon.2019.04.024

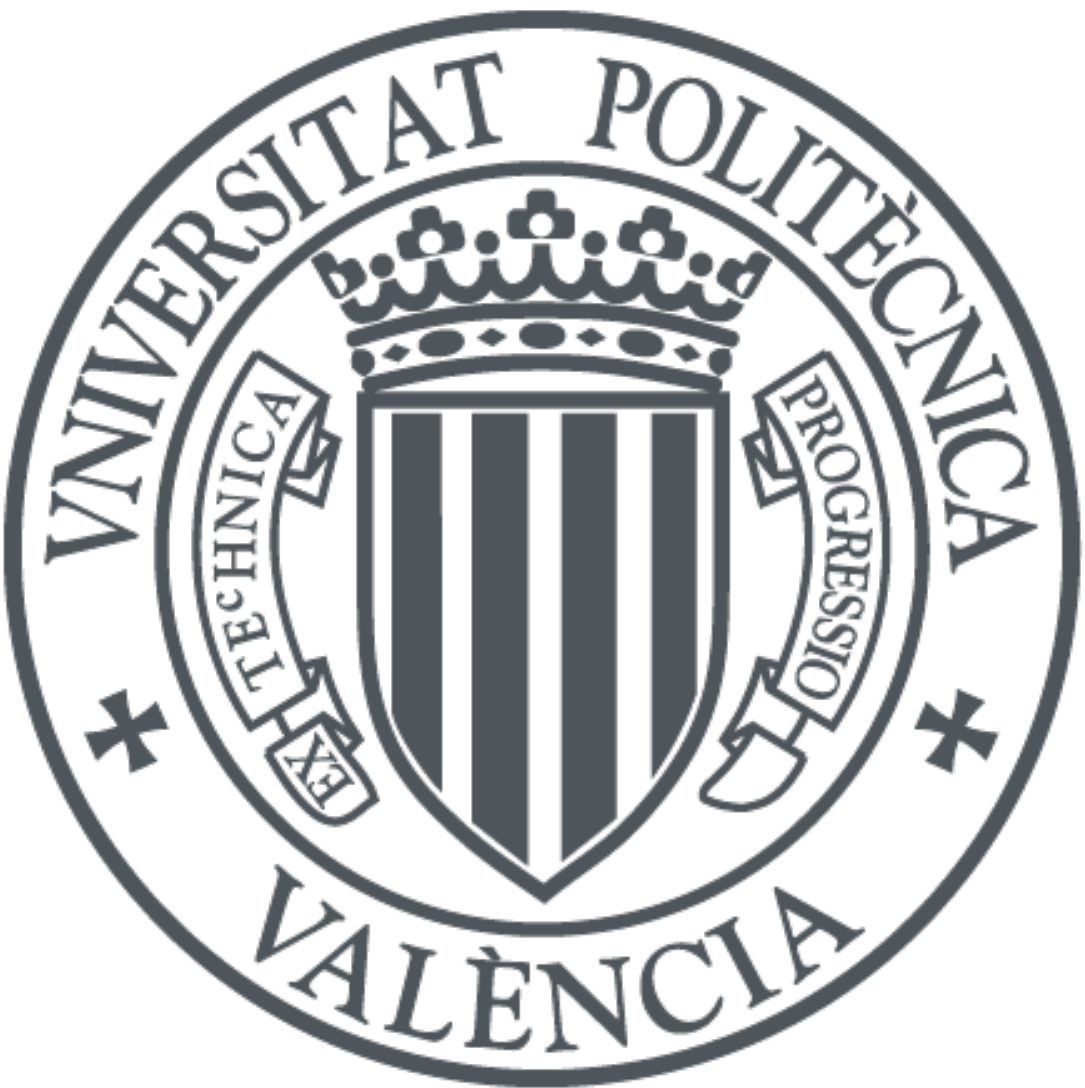

The final publication is available at

https://doi.org/10.1016/j.autcon.2019.04.024

Copyright Elsevier

Additional Information 


\title{
OPTIMIZATION OF REINFORCED CONCRETE BUILDING FRAMES WITH AUTOMATED GROUPING OF COLUMNS
}

\author{
Juliana Triches Boscardin ${ }^{1}$, Victor Yepes ${ }^{2}$, Moacir Kripka ${ }^{1}$ \\ ${ }^{1}$ Civil and Environmental Engineering Graduate Program, University of Passo Fundo, Passo \\ Fundo, Brazil \\ ${ }^{2}$ Institute of Concrete Science and Technology (ICITECH), Universitat Politecnica de \\ Valencia, 46022, Valencia, Spain
}

\begin{abstract}
:
In structural design, it is common practice to adopt the same cross-section dimensions for a group of elements. This procedure is mainly for practical and aesthetic reasons, as well as to reduce labour costs, but it also has a positive effect of reducing the number of variables, which simplifies the usual trial and error design process. On the other hand, the total materials cost obtained is closely related to this grouping. Based on this, the present work aims to minimize the cost of reinforced concrete plane frames considering the automated grouping of columns. To achieve this objective, an optimization software was developed by the association of matrix structural analysis, dimensioning and optimization. The sections dimensions, the area of steel and the concrete strength of beams and columns were taken as design variables. For a given maximum number of groups, the optimum grouping and the corresponding values to design variables are obtained. The strategy proposed in this paper to obtain the grouping reduces significantly the number of infeasible candidate solutions during the search process and avoid the proposition of unrealistic designs. For the optimization, a variant of the Harmony Search method was adopted. Some structures were analyzed in order to validate the application of the proposed formulation, as well as to verify the influence of the grouping of elements on the final results. In these structures, it was possible to observe a significant additional reduction in the total cost when automated grouping is performed regarding a uniform grouping, even when a small number of groups is considered. For the 20floor building frame analyzed, the cost reduction from uniform to automated grouping varied from 5.53 to $7.35 \%$. The influence of the concrete strength on optimal results was also investigated, indicating a cost reduction of $9.74 \%$ from best (40 MPa) to worst case (20 MPa). In general, it can be concluded that, when applied in conjunction with the usual design variables, the proposed procedure can enable a significant additional economy, without affecting the structural safety.

Keywords: optimization, automated grouping, reinforced concrete, plane frames, Harmony Search
\end{abstract}

\section{INTRODUCTION}

In the dimensioning of a structure, the designer needs to use his experience and intuition to obtain the configuration and the dimensions of the elements that best meet the aspects of safety 
and functionality, this procedure being performed through a process of trial and error. On the other hand, this process does not guarantee the most economical option, since there is a huge number of possible solutions to a given problem. The use of optimization techniques can partially solve this problem, since they can lead to the best solution to a given problem, or at least to a very good improvement on the design obtained by the traditional procedure.

When dealing with reinforced concrete structural optimization, usually the objective is to minimize the total cost, comprising the costs of the concrete, steel and formwork, subject to constraints related to standards requirements and strength and serviceability criteria. More recently, other objectives have been considered, such as the minimization of environmental impact, and the maximization of constructability or the overall safety. These objectives can be considered individually [1-3] or within a multi-objective perspective [4-8].

The number of design variables constitutes an important aspect in optimization problems, since it defines the dimensions of the search space. Considering the practical situation according to which the variables can assume just discrete values (e.g. sections of steel bars), the number of possible combinations grows dramatically with the addition of a new design variable to the problem. For this reason, even for a simple structure with fixed geometry, the number of design variables needs to be reduced. Besides the reduction in the number of design variables, the grouping of elements is commonly adopted due to aesthetic reasons (uniformization of elements dimensions), as well as labour costs (e.g. related to formworks reutilization), bulk fabrication and/or construction simplification. On the other hand, former studies indicate that total materials cost is closely related to this grouping [9].

This work presents the minimization of the cost of reinforced concrete plane frames considering the automated grouping of columns. To achieve this objective, an optimization software was developed by the association of matrix structural analysis, dimensioning and optimization. The sections dimensions, the area of steel and the concrete strength of beams and columns were taken as design variables. For a given maximum number of groups, the optimum grouping and the corresponding values to design variables are obtained. Sizing was compliant with the Brazilian code ABNT NBR 6118/2014 [10], according to which ultimate and serviceability limit states are checked. A strategy to reduce the number of infeasible candidate solutions during the search process is also proposed, making the search process more efficient. In addition, this strategy avoids the proposition and analysis of unrealistic designs. For the optimization, a variant of the Harmony Search method was adopted. The choice of this method was made based on other successful applications developed by the authors regarding reinforced concrete structures, e.g. [11-13].

The automated grouping of elements can be made by the usage of cardinality constraints, which defines the maximum number of different sections or characteristics allowed to a set of elements. The few studies found in the literature regarding automated grouping of elements concentrate on steel structures, namely trusses [14-17] and frames [18,19]. In [20], Carvalho et al. studied the influence of automated material grouping on topology optimization of trusses. Liu et al. [21] obtained the optimal variable grouping for pile foundations. The automated grouping applied to reinforced concrete building grillages was first studied by Kripka, Medeiros and Lemonge [22], and in greater depth in a subsequent work [13]. It must be stressed that, in general, the optimization of reinforced concrete structures consists in a few studied problems when compared to other structural materials [23]. Due to this, one difficulty in working on the optimization of reinforced concrete frames is the lack of benchmark problems [24].

This work is structured as follows. The first section introduces the motivation and the objective of the present work. The second section describes the optimization method, Harmony Search, while the formulation of the optimization problem is presented in the third section, together with the grouping strategy. The fourth section presents three structures analyzed, 
aiming to illustrate the proposed procedure. Finally, the fifth section describes the conclusions of the study.

\section{HARMONY SEARCH OPTIMIZATION METHOD}

The last few decades have witnessed the consolidation of the applications of metaheuristic methods to a wide range of optimization problems, including those related to structures. This fact can be attributed mainly to the flexibility of these methods, since they do not need the calculation of derivatives and can be easily adapted to handle discrete design variables, which represent more realistically most structural problems. It must be stressed that, since heuristic methods need a large number of function evaluations, they should not be used for all kinds of problems, but especially for those for which mathematical programming does not perform well.

Heuristic methods are numerous, most of them being just a small variation of previous methods $[25,26]$. Despite the great popularity of methods such as Simulated Annealing and Genetic algorithms, the Harmony Search algorithm has been successfully applied in various research areas [27].

The Harmony Search algorithm, or simply HS, is a metaheuristic that was proposed by Geem, Kim and Loganathan [28], which makes an analogy with the musical improvisation of jazz, where musicians try to find, through repeated attempts, the perfect harmony (best solution to a problem). Iterations are called improvisations. Variables correspond to musical instruments, and the values for variables are the sounds of instruments. Each solution is called harmony, and the calculation of the objective function is called aesthetic estimation. The method can be summarized in the following main steps:

- Definition of the objective function, design variables, constraints and parameters of the algorithm. The main parameters are Harmony Memory Size (HMS), Harmony Memory Considering Rate (HMCR), Pitch Adjusting Rate (PAR) and Maximum Improvisation (MI).

- Initialization of Harmony Memory (initial solutions). Since HS is a population-based method, Harmony Memory (HM) can be represented by a matrix, as in Eq. (1). Each line of the matrix corresponds to a solution vector, where the number of rows HMS is the population size and the number of columns corresponds to the number of design variables $\mathrm{N}$ of the problem. According to the original version of the method, harmonies are randomly generated.

$$
H M=\left[\begin{array}{ccc}
x_{1}^{1} & \cdots & x_{N}^{1} \\
\vdots & \ddots & \vdots \\
x_{1}^{H M S} & \cdots & x_{N}^{H M S}
\end{array}\right]
$$

- Generation of a new harmony (or improvisation), using parameters PAR (Pitch Adjusting Rate) and HMCR (Harmony Memory Considering Rate). For each variable of the new candidate solution, a random number between 0 and 1 is generated. If the random number is less than HMCR, the value of the respective variable in the new solution vector is retrieved from the existing Harmony Memory. If the random number is greater (probability equal to 1HMCR), a new value for the variable is generated, as in Eq. (2):

$$
x_{i}^{\prime} \leftarrow\left\{\begin{array}{c}
x_{i}^{\prime} \in\left\{x_{i}^{1}, x_{i}^{2}, \ldots, x_{i}^{H M S}\right\} \text { with probability HMCR } \\
x_{i}^{\prime} \in X_{i} \text { with probability }(1-H M C R)
\end{array}\right\}
$$


The choice of this new value can be done in two different forms, according to Eq. (3). Again, a random number between 0 and 1 is generated and compared to the parameter PAR. If the number is less than PAR, Harmony Memory is considered, but with a little adjustment, according to Eq. (4). This adjustment is defined by $b w$ (maximum variation of tone) and a random number. If this is greater than PAR (probability equal to 1-PAR), the new value for the variable is randomly generated within the interval of possible solutions.

$$
\begin{aligned}
& \text { Adjustment of the note } x_{i}^{\prime} \leftarrow\left\{\begin{array}{c}
Y E S, \text { with probability } P A R \\
N O T, \text { with probability }(1-P A R)
\end{array}\right\} \\
& x_{i}^{\prime} \leftarrow x_{i}^{\prime} \pm \text { random number } * b w
\end{aligned}
$$

In more recent versions of HS, the parameter $b w$ was renamed as $F W$, or fret width, in order to adapt the nomenclature of the musical analogy.

- Checking whether the new harmony (improvisation) is better than the worst harmony of Harmony Memory (HM), relative to the objective function. If this condition is confirmed, the new harmony replaces the worst harmony of HM.

-Verification of stopping criterion, or maximum number of improvisations MI. A new improvisation is generated and checked.

Several variations of the original method have been proposed by other researchers [29]. Most of them try to make HS less dependent on the parameters definition, and to develop a more extensive search space. An extensive study regarding these variations can be found, e.g., in [30] and [31].

The algorithm adopted in the present work considers the inclusion of the dynamic variation of parameters PAR and $b w$ proposed by Mahadavi, Fesanghary and Damangir, called Improved Harmony Search, or IHS [32]. In addition to IHS, our algorithm considers the following modifications regarding the original HS, in a version named Modified Improved Harmony Search, or MIHS [33]: instead of generating Harmony Memory randomly, one predefined solution (or more) can be included in the Harmony Memory. It can account for the designer's knowledge regarding the specific problem; aiming to avoid premature convergence to a local minimum, the Harmony Memory is restarted when all solutions achieve the same value. Only the best current solution is kept in this new HM. This procedure is similar to reannealing, adopted in the Simulated Annealing method; finally, as an additional stopping criterion to avoid unnecessary calculations, the algorithm terminates the search when the best solution found does not vary after successive restarts, NR being the considered number of restarts. The reader interested can obtain further details of MIHS in [33], including a comparison with Simulated Annealing regarding convergence rate and average number of iterations when applied to columns optimization.

\section{FORMULATION OF THE OPTIMIZATION PROBLEM}

This work aims to minimize the cost of reinforced concrete building plane frames, taking into account the costs of steel, concrete and formworks. The developed formulation was adapted from previous studies regarding building grillage optimization [34] and columns optimization [35]. Preliminary results for plane frames without considering cardinality constraints were presented in [36]. The remainder of this section describes the design variables, the objective 
function and the constraints adopted in the formulation, as well as the grouping strategy proposed.

\subsection{Design variables}

The design variables are represented by the cross-sectional dimensions of columns, as well as the number of bars and their corresponding diameter, according to Fig. 1, where:

$\mathrm{X} 1$ : height of concrete section $(h)$;

$\mathrm{X} 2$ : diameter of the four corner bars;

X3: number of bars in the two layers parallel to base width bp (fixed);

$\mathrm{X} 4$ : diameter of the bars in the two layers parallel to bp;

X5: number of layers with two bars parallel to X1;

X6: diameter of the bars in the layers parallel to X1.

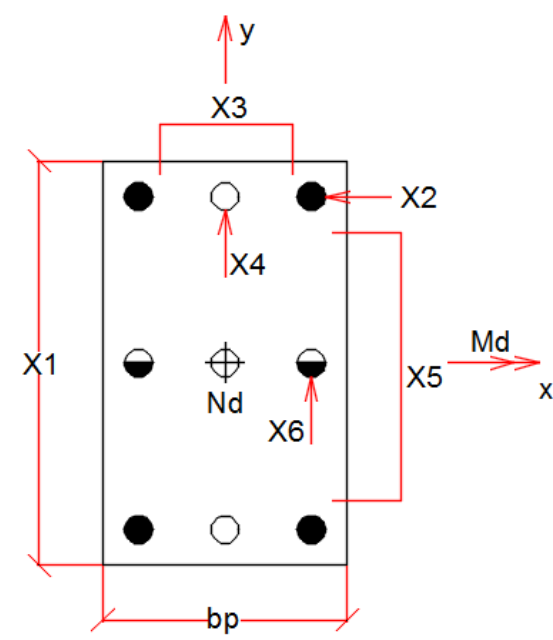

Figure 1 - Design variables for columns

In Fig. 1, Md and Nd represent the bending moment and the axial stress, respectively, from which the strength of the columns is verified.

The possible values to be assumed for each design variables are:

$$
\begin{array}{r}
\mathrm{X} 1 \in[20 ; \ldots ; 300], \text { in } \mathrm{cm} \\
\mathrm{X} 3, \mathrm{X} 5 \in[0 ; \ldots ; 18]
\end{array}
$$

$\mathrm{X} 2, \mathrm{X} 4, \mathrm{X} 6 \in[10 ; 12,5 ; 16 ; 20 ; 22 ; 25]$, in $\mathrm{mm}$

The design variables were considered to assume only discrete values, with the dimensions of concrete sections being multiples of $5 \mathrm{~cm}$, and the diameters of steel bars limited to those available commercially. It can be observed that the intervals are large enough to not interfere on the results of the optimization process. On the other hand, the computational cost of this procedure is increased, since the search space became very large.

For the beams, aiming to simplify the formulation, only the height is considered as a design variable (represented as X7 in Fig. 2), the transversal and longitudinal steel area being obtained for this section (beam width $b v$ is fixed). Although beams reinforcement would be better represented as a discrete variable, as considered to columns, many research studies 
related to beams optimization assumed that treating the design variables as continuous leads to sufficiently accurate optimal results [37]. In addition, the compression reinforcement was not considered, based on former works of authors regarding grillage beams, which indicated that this consideration does not influence the optimum results $[9,34]$.

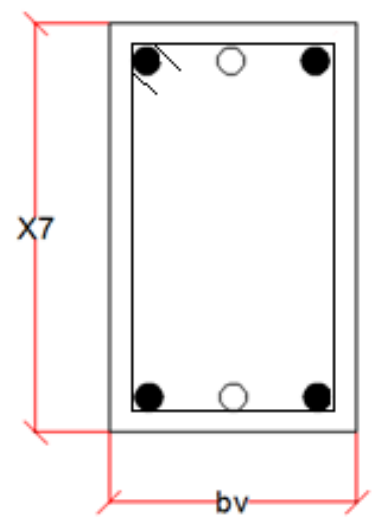

Figure 2 - Design variable for beams

The interval of possible values to be assumed for beams height is

$$
X 7 \in[10 ; \ldots ; 300] \text {, in } \mathrm{cm}
$$

All the beams of a given structure were considered to have the same height. Since each group of columns $N G$ is composed of six design variables, as shown in Fig. 1, the total number of design variables $(\mathrm{N})$ is:

$$
\mathrm{N}=6 . \mathrm{NG}+1
$$

It is important to note that, since all design variables can assume only discrete values, even to a small size problem, and the wide range of values, the problems falls into a not so simple combinatorial problem.

\subsection{Objective function}

The total cost of a material was obtained considering the unit cost and its corresponding amount. Steel was quantified by mass $(\mathrm{kg})$, concrete by volume $\left(\mathrm{m}^{3}\right)$, and formwork by area $\left(\mathrm{m}^{2}\right)$. Based on this, the objective is given by Eq. (6), where $C t$ corresponds to the overall cost of the frame, composed of beams and columns; $P s, A f$, and $V c$ refer to the amounts of steel bars, formworks, and concrete, respectively; and $C s, C f$, and $C c$ represent the unit costs of these materials, respectively.

$$
\mathrm{Ct}=\mathrm{Ps} . \mathrm{Cs}+\mathrm{Af} \cdot \mathrm{Cf}+\mathrm{Vc} \cdot \mathrm{Cc}
$$

\subsection{Constraints}

All design variables must satisfy the prescriptions of the Brazilian standard [10] for Reinforced Concrete Design Structure, regarding strength and durability. 
The following constraints are specific to columns. The constraints expressed in Eqs. (7) and (8) are related to the axial force and bending moment, respectively:

$$
\begin{aligned}
& 1-\frac{N r d}{N s d} \leq 0 \\
& 1-\frac{M r d}{M s d} \leq 0
\end{aligned}
$$

The following constraints are related to the dimensional limits of the columns (Eqs. (9) and (10)), steel bars spacing $e$ (Eqs. (11) and (12)), and steel ratio $\rho$ (Eqs. (13) and (14)), according to the Brazilian Standard. In addition, Eq. (15) imposes a minimum cross-sectional dimension for the columns, and Eqs. (16) to (18) refer to the maximum relations among the longitudinal steel bar diameters and column dimensions.

$$
\begin{aligned}
& 1-\frac{x 1}{b p} \leq 0 \\
& 1-\frac{5 \cdot b p}{x 1} \leq 0 \\
& 1-\frac{e}{e m i n} \leq 0 \\
& 1-\frac{e m a ́ x}{e} \leq 0 \\
& 1-\frac{\rho}{\rho m i n} \leq 0 \\
& 1-\frac{\rho m a ́ x}{\rho} \leq 0 \\
& 1-\frac{b p \cdot x 1}{360} \leq 0 \\
& 1-\frac{b p}{8 . x 2} \leq 0 \\
& 1-\frac{b p}{8 \cdot x 4} \leq 0 \\
& 1-\frac{b p}{8 . x 6} \leq 0
\end{aligned}
$$

The constraint expressed in Eq. (19) limits the slenderness ratio $\lambda$ to short and medium columns.

$$
1-\frac{90}{\lambda} \leq 0
$$

The constraints stated in Eq. (20) are related to an additional constructive aspect of the frame, by imposing that the length of a column situated in an upper floor $x l(u)$ cannot be greater than the length of the column immediately below, $x l(l)$. 


$$
1-\frac{x 1(u)}{x 1(l)} \leq 0
$$

Regarding beams constraints, the stresses considered were related to the bending moments (Eq. (21)) and shear stresses. To check for shearing, the adopted standard states that the strain that the concrete should withstand in compressed struts, $V R d 2$, should be greater than the respective stress VSd, (Eq. (22)), and the strength of the concrete and reinforcements in the tensioned struts, VRd3, should be larger than the working stress VSd, as described in Eq. (23). Beams deflections limits were not considered as design constraints.

$$
\begin{aligned}
& 1-\frac{M r d}{M s d} \leq 0 \\
& 1-\frac{V R d 2}{V s d} \leq 0 \\
& 1-\frac{V R d 3}{V s d} \leq 0
\end{aligned}
$$

As in the case of columns, constraints were considered in relation to the steel ratio (Eqs. (24) and (25)). In addition, the ratio between the fractions of the bending moment absorbed by compression and tension in double reinforcements, MAs and MAs, respectively, should not exceed 30\%, to prevent a large concentration of reinforcements (Eq. (26)).

$$
\begin{aligned}
& 1-\frac{\rho}{\rho \min } \leq 0 \\
& 1-\frac{\rho \text { máx }}{\rho} \leq 0 \\
& 1-\frac{0,30 M A S}{M A S^{\prime}} \leq 0
\end{aligned}
$$

In relation to the global behaviour of the frame, the maximum deflection $\delta$ on top was limited to $1 / 1700$ of the building height $H$, according to Eq. (27):

$$
1-\frac{H}{1700 . \delta} \leq 0
$$

Regarding the adoption of Brazilian standard, it is important to emphasize that standard is recognized by ISO (International Organization for Standardization) as an international code, being possible to make its use in any country. It is very similar to Eurocode 2 in many aspects, so it is expected that the dimensioning would not be very different by the usage of one or these two codes, or even of other similar code. The main differences among Brazilian code and other widely adopted standards (Eurocode, ACI and CEB-FIP) are related to constructive aspects such as bar spacing, steel ratio and dimensional limits, and not to strength itself. Due to the abovementioned aspects, it is expected that the results of the present study will not be affected by a code changing.

The aforementioned constraints are usual in reinforced concrete building frames, with some variations depending on the standard and design criteria adopted. The novelty presented in this 
paper is the inclusion of automated grouping of columns by the usage of cardinality constraints, which defines the maximum number of different sections or characteristics allowed to a set of elements. Once defined the maximum number of different columns as $N G$, or number of groups, each column is assigned to one of these groups. It is important to emphasize that the number of groups $N G$ defined by the user is in fact an upper bound to this value, since optimized result can attribute same characteristics to more than one group of columns. The grouping of columns corresponds to an intermediate situation between a unique section to all columns along the height of the building (more material consuming) and the adoption of a different section to each floor (e.g. more labor costs). Usual automated grouping strategy attributes, by chance, a column to a given group. In this case, the same section could be linked to columns of floors \#1 and \#3, for example, and a bigger section to floor \#2. This situation corresponds to a nonrealistic design and is considered an unfeasible solution to optimization problem by the adoption of a constraint such as in Eq. (20). The strategy proposed in this paper considers the generation of a new grouping through additional variables taken as the limits to each change, as illustrated in Fig. 3. In this case, the number of infeasible candidate solutions is dramatically reduced, adding more effectivity to the optimization procedure. As illustrated in Fig.3, just a few additional variables (NG-1), indicate the floors limiting each group.

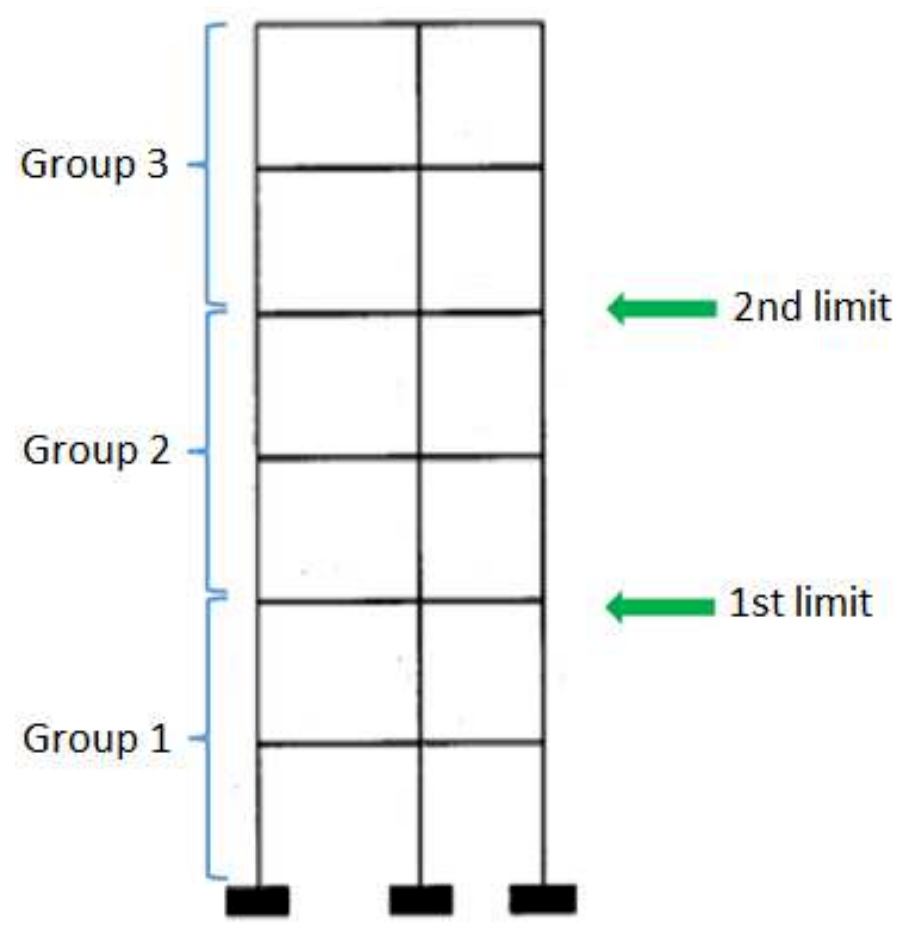

Figure 3 - Grouping of columns

The proposed formulation was implemented in Fortran computer language, by association of the Harmony Search algorithm and a routine developed for plane frame structural analysis by displacement method. The input data are similar to those usually needed by structural programs, such as geometry, materials, elements dimensions and applied loads, self-weight being computed automatically. In addition, the unit costs of materials must be provided by the user, as well as the maximum number of groups NG. Although the optimized results are not strongly dependent on the dimensions initially adopted, the user is allowed to input previous cross- 
section dimensions for the elements, in order to take advantage of his/her previous experience about the problem. This solution will integrate the initial population matrix, as in Eq. (1). In computational implementation, the characteristic strength of concrete was also added as design variable, but this was not considered in the present paper. The flowchart in Fig. 4 summarizes the main steps involved in the optimization process. 


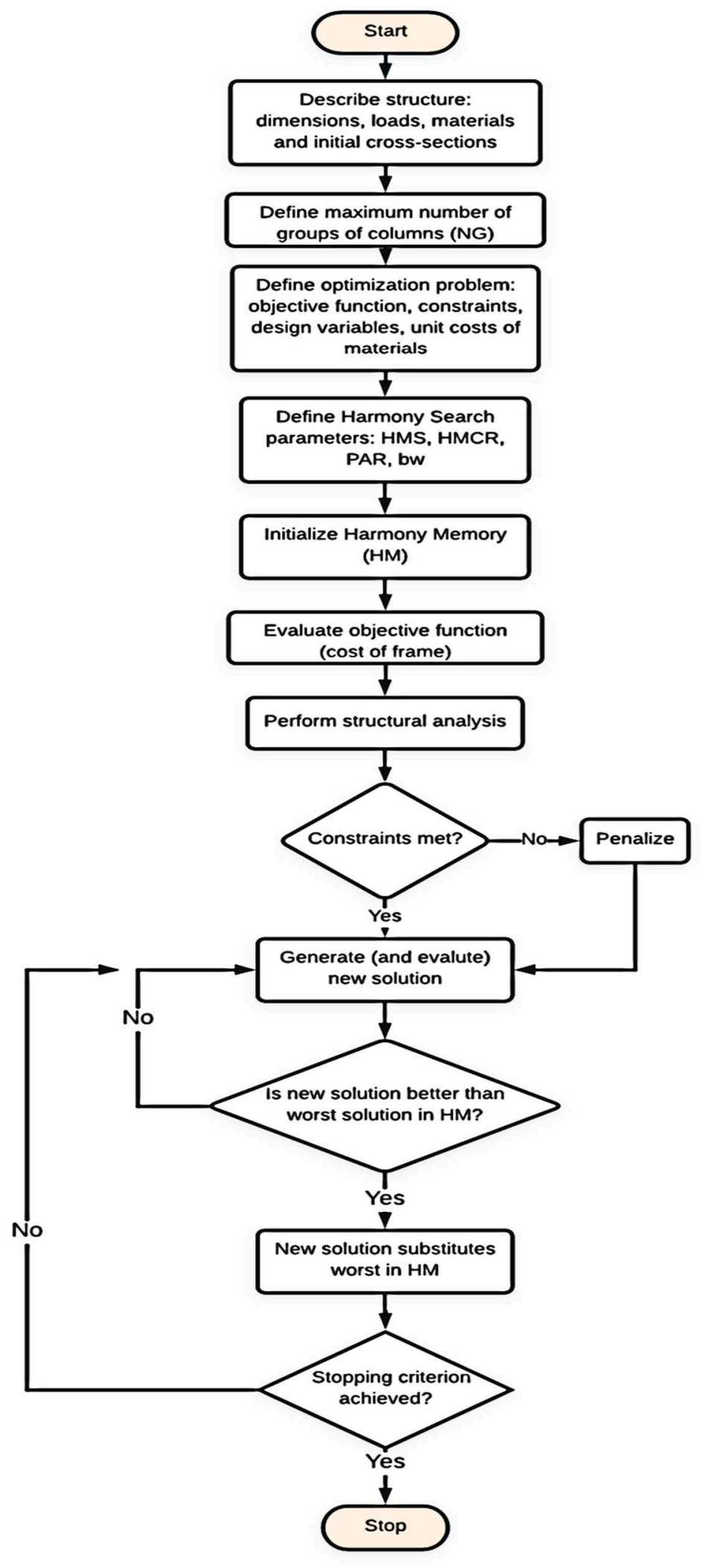

Figure 4 - Flowchart of optimization process 


\section{NUMERICAL EXAMPLES}

In order to validate the proposed procedure, as well as to investigate the influence of the grouping of columns on the optimized results, some numerical simulations were developed. Some simplifications were adopted, as follows: in all the examples analyzed, a single load combination was considered; a single cross-section is allowed for all columns located on the same floor. In spite of the fact that these simplifications still limit the application of the program to practical designs, they do not influence the results and consequent comparisons, since the considerations were the same for all structures analyzed.

The results presented in the following items were the best obtained for 10 independent runs, each run needing about 900 seconds on a computer with Intel Core i7 CPU @ $2.7 \mathrm{GHz}$ and 16 GB of RAM.

\subsection{Example 1}

The first structure analyzed was adapted from Boito [38]. It consists of a 12-storey single bay frame, submitted to vertical uniform loads applied to all beams (Fig. 5). Beam and column widths were set at $0.2 \mathrm{~m}$. The unit costs of materials are listed in Table 1 in Brazilian Currency (Reais, R\$). CA-50 steel was considered.

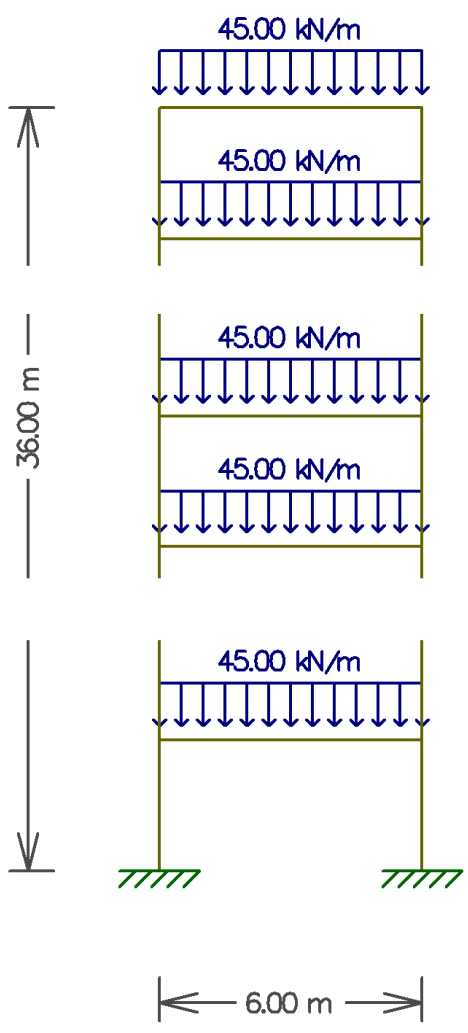

Figure 5 - Example 1: 12-storey single bay frame 
Table 1 - Unit costs of materials for example 1

\begin{tabular}{|c|c|c|c|}
\hline $\begin{array}{c}\text { Concrete strength } \\
(\mathrm{MPa})\end{array}$ & $\mathrm{Cc}\left(\mathrm{R} \$ / \mathrm{m}^{3}\right)$ & $\mathrm{Cs}(\mathrm{R} \$ / \mathrm{kg})$ & $\mathrm{Cf}\left(\mathrm{R} \$ / \mathrm{m}^{2}\right)$ \\
\hline $\mathrm{C}-20$ & 315.00 & & \\
\hline C-30 & 339.31 & & \\
\hline C-40 & 364.73 & \multirow{2}{*}{5.33} & \multirow{2}{*}{90.21} \\
\hline C-50 & 486.31 & & \\
\hline C-60 & 624.47 & & \\
\hline C-70 & 750.00 & & \\
\hline C-80 & 862.10 & & \\
\hline C-90 & 950.00 & & \\
\hline
\end{tabular}

Initially, the same size for all columns was considered in the optimization. After this, the structure was optimized to a growing number of different groups, up to four (corresponding from 7 up to 25 design variables). Figure 6 shows the optimized results obtained for the structure of the example, considering C-30 concrete strength for all elements. These results were obtained considering both a uniform distribution of elements per group and the automated grouping. It's important to emphasize that all presented results are optimized. The only difference is the fact that, according the proposed procedure, the definition of groups is also a task the optimization software.

It can be verified that a good saving can be achieved as the number of different crosssections grows. In addition, even with a small number of groups, a significant cost reduction can be obtained when the grouping is included among the variables. For example, for $\mathrm{NG}=3$ (three groups), automated grouping led to a better result than when considering four groups of a uniform number of columns. Figure 7 illustrates the resulting optimized grouping (sizes not in scale).

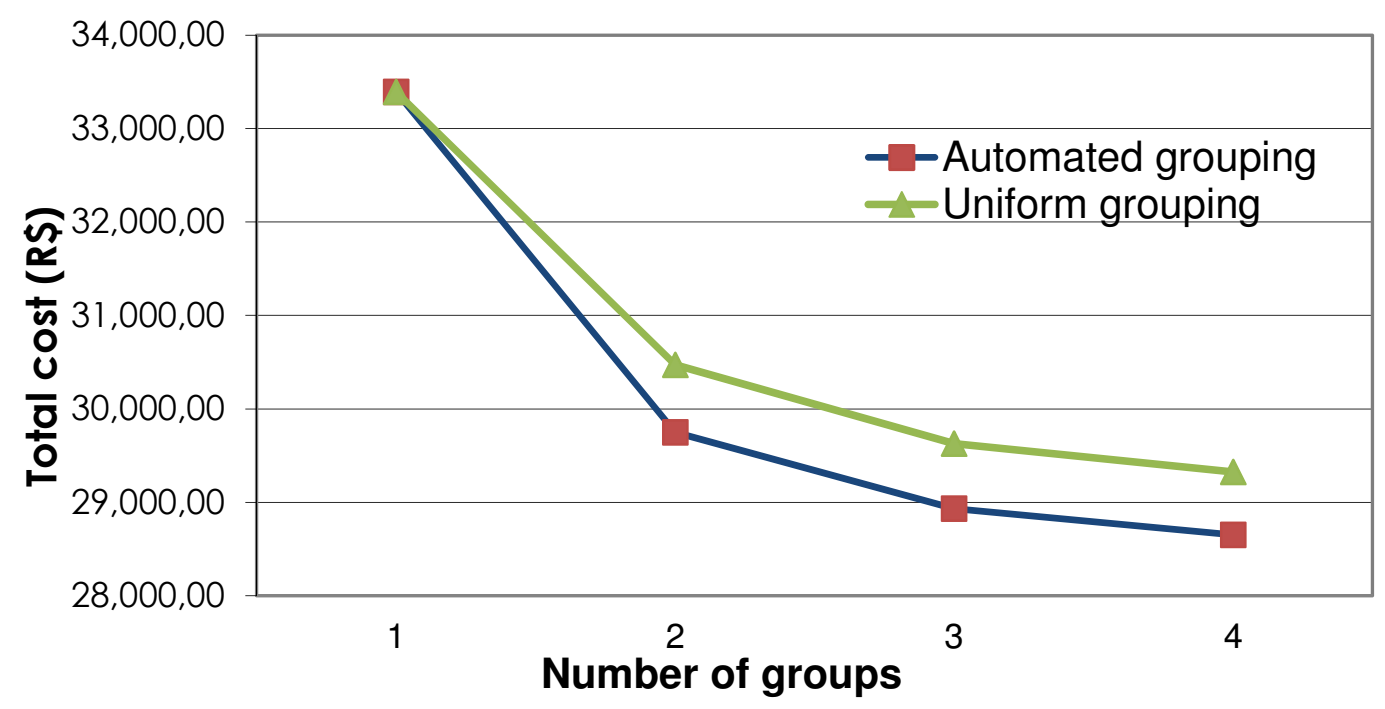

Figure 6 - Example 1: optimized results 

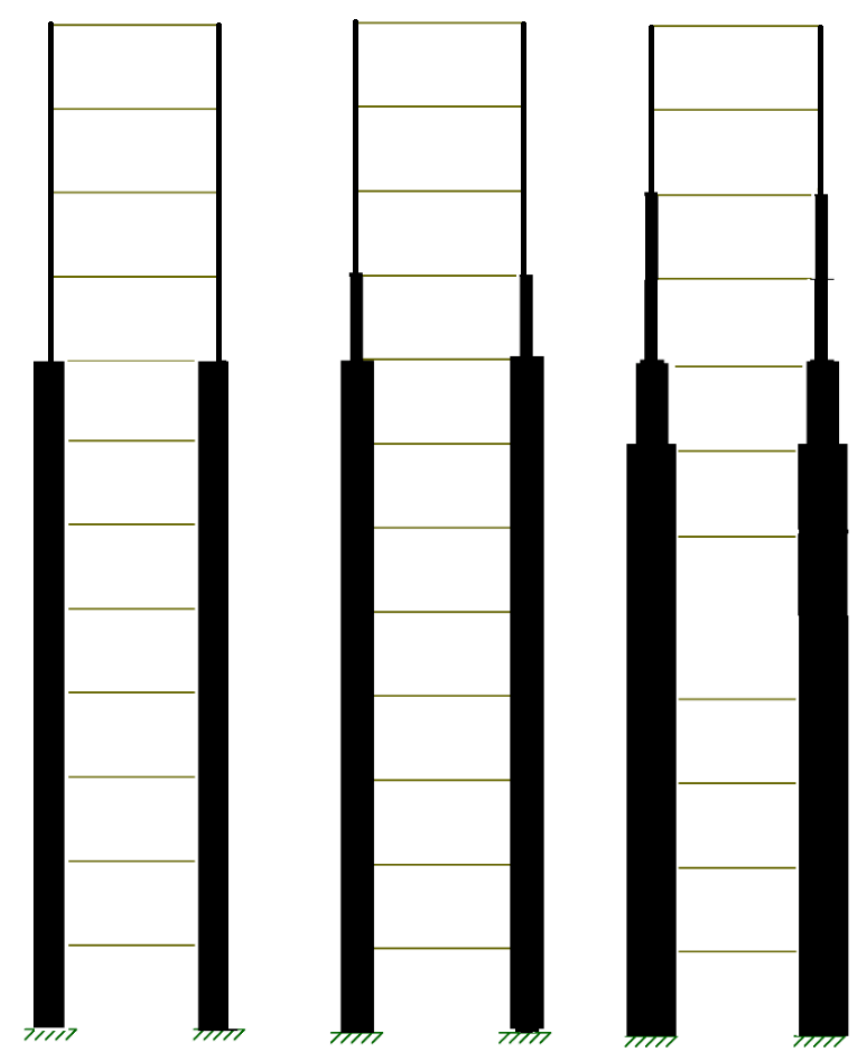

Figure 7 - Optimized groups for $\mathrm{NG}=2,3$ and 4, respectively (sections not in scale)

Although in several applications concrete strength can be considered as an additional design variable, we added this information as an input data in our software, in order to allow a better understanding of its influence on final cost. Based on this, figure 8 shows the results obtained with optimized grouping for all the concrete strengths listed in Table 1 (from C-20 to C-90), considering $\mathrm{NG}=4$. It can be observed that the best result is obtained for an intermediate class of concrete (C-40), with the worst result corresponding to the lowest concrete strength (difference of $8.51 \%$ ). Table 2 summarizes the results for each concrete strength. The cost of columns varied from $47.84 \%$ of the total cost for C-20 concrete up to $43.34 \%$ for C- 90 . According to the same table, it can be verified that the volume of concrete reduced by $40 \%$ from C-20 to C-90, while the steel ratio increased from 0.9 to $1.75 \%$. For the best result, a steel ratio of $1.44 \%$ was obtained. 


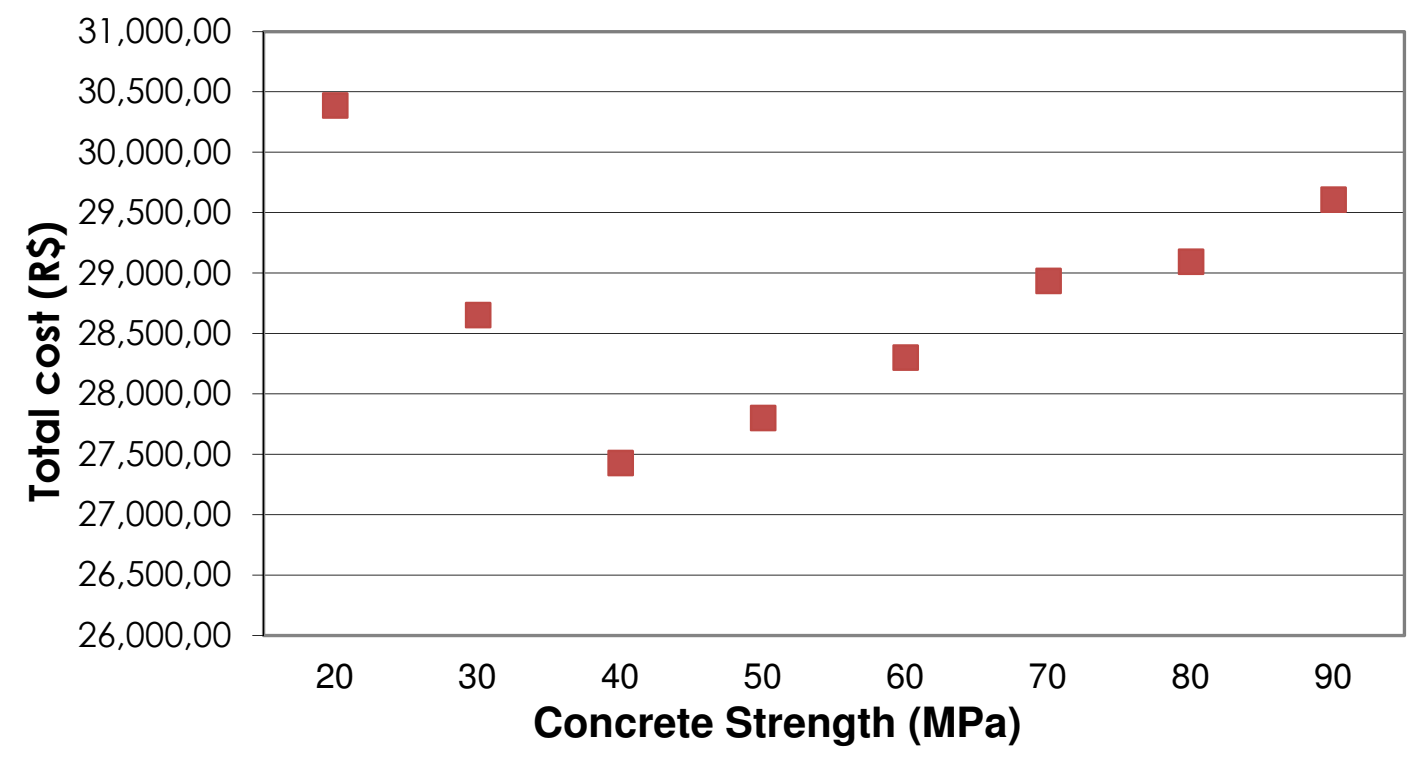

Figure 8 - Results for $\mathrm{NG=4}$ and variable concrete strength

Table 2 - Results for example 1 with different concrete strength and $\mathrm{NG}=4$

\begin{tabular}{|c|c|c|c|c|c|c|}
\hline $\begin{array}{c}\text { Concrete } \\
\text { strength } \\
(\mathrm{MPa})\end{array}$ & $\mathrm{Vc}\left(\mathrm{m}^{3}\right)$ & $\mathrm{Ps}(\mathrm{kg})$ & $\mathrm{Af}\left(\mathrm{m}^{2}\right)$ & $\begin{array}{c}\text { Ccolumns } \\
(\mathrm{R} \$)\end{array}$ & $\begin{array}{c}\text { Cbeams } \\
(\mathrm{R} \$)\end{array}$ & $\begin{array}{c}\mathrm{Ct} \\
(\mathrm{R} \$)\end{array}$ \\
\hline 20 & 16.68 & $1,161.00$ & 210.00 & $14,536.29$ & $15,850.14$ & $30,386.43$ \\
\hline 30 & 14.04 & $1,374.33$ & 183.60 & $13,180.42$ & $15,471.25$ & $28,651.67$ \\
\hline 40 & 12.60 & $1,419.86$ & 169.20 & $12,521.27$ & $14,905.70$ & $27,426.97$ \\
\hline 50 & 12.18 & $1,312.05$ & 165.00 & $12,470.35$ & $15,330.79$ & $27,801.14$ \\
\hline 60 & 11.82 & $1,193.15$ & 161.40 & $12,747.32$ & $15,553.32$ & $28,300.64$ \\
\hline 70 & 10.5 & $1,443.05$ & 148.20 & $12,993.57$ & $15,942.01$ & $28,935.58$ \\
\hline 80 & 10.26 & $1,331.20$ & 145.80 & $12,765.44$ & $16,327.61$ & $29,093.05$ \\
\hline 90 & 10.08 & $1,321.31$ & 144.00 & $12,831.46$ & $16,592.27$ & $29,608.83$ \\
\hline
\end{tabular}

\subsection{Example 2}

The second structure studied consists of a 20-floor three-bay frame adapted from Kaveh and Zakian [39], shown in Fig. 9. Together with horizontal loads, a vertical load of $31.3 \mathrm{kN} / \mathrm{m}$ was applied to all beams and added to the self-weight of the elements. Concrete C-25 and steel CA50 were adopted. The unit costs considered are: US $\$ 60 / \mathrm{m}^{3}$ for concrete; US\$ $0.9 / \mathrm{kg}$ for steel, and US\$ $18 / \mathrm{m}^{2}$ for formworks. It must be stressed that, since Kaveh and Zakian [39] optimized the frame considering seismic loads, which is not regularly supported by Brazilian Standard, the optimized results can't be compared. In addition, in [38], a fixed grouping was considered. 


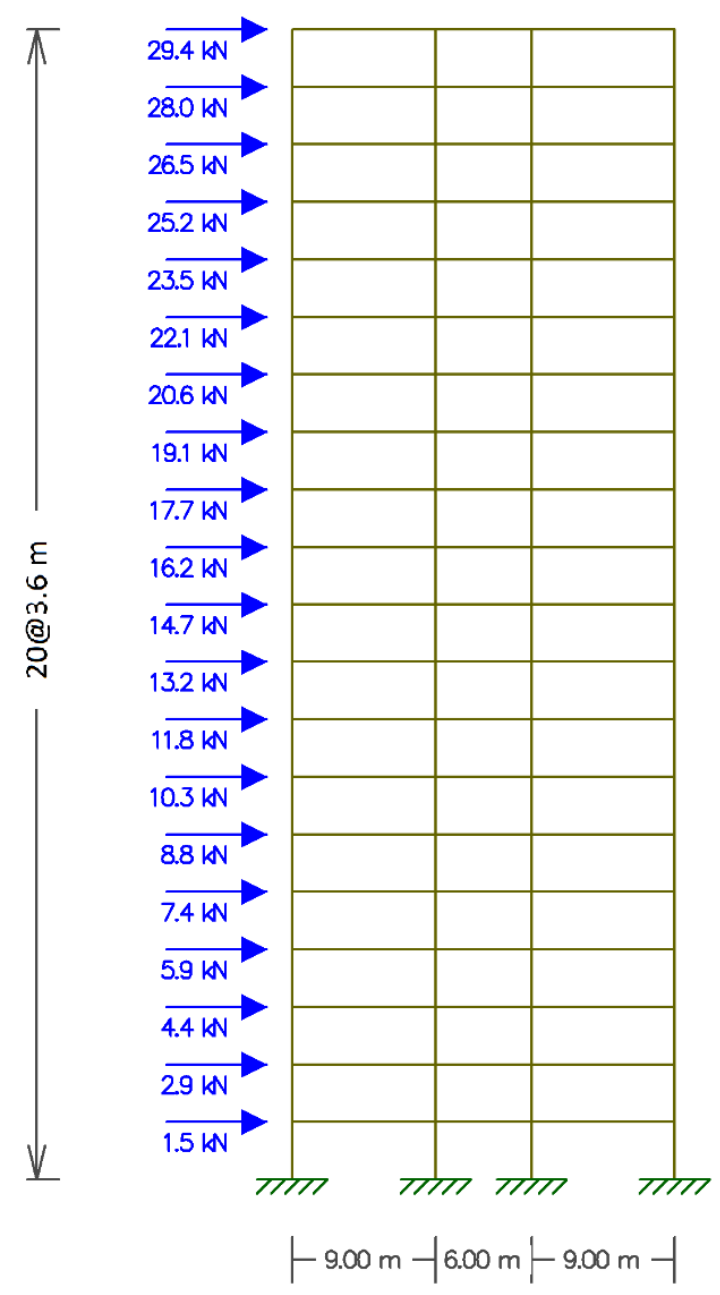

Figure 9 - Example 2: 20-floor building frame

As in the first example, the structure was optimized to a variable number of groups, from one to five in this case ( 7 to 31 design variables). The results obtained both for uniform and for automated grouping are illustrated in Fig. 10. According to this, even for a small group, a remarkable saving was obtained. For example, for $\mathrm{NG}=2$, the cost reduction with automated grouping, in regard to uniform grouping, is $7.35 \%$. In addition, the result obtained with automated grouping composed of only two sections $(\mathrm{NG}=2)$ is even better than that obtained for $\mathrm{NG}=5$ when uniform grouping is considered (reduction of $2.61 \%$ ). It can be seen that when the composition of grouping is optimized, even a small number of different columns sections can generate an additional cost saving. It must be stressed that other indirect benefits, such as reduction in labour with formworks cutting and adaption are not directly taken into account in the formulation. 


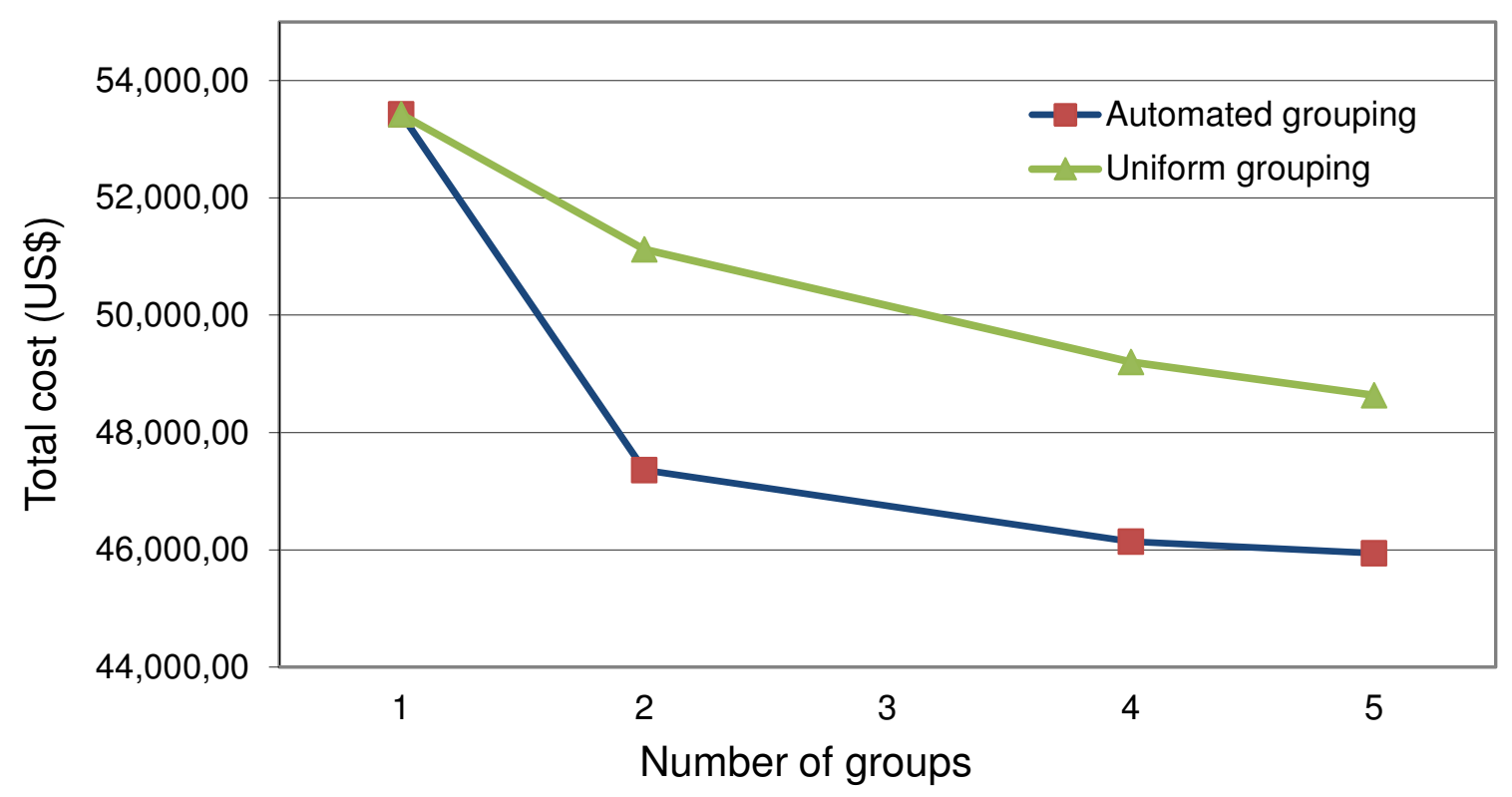

Figure 10 - Example 2: optimized results

Table 3 presents beams and columns optimized dimensions and corresponding grouping to uniform and automated grouping, as well as the corresponding total cost. Through the table, it can be observed that to automated grouping a huge number of elements is allocated in the lowest group, with the remaining columns assuming small lengths. It is interesting to note that the groupings are quite similar to those obtained in Example 1, to which only gravity loads were considered. It can also be verified that beam height achieved the same value in all optimized solutions.

Table 3 - Results for example 2 to uniform grouping

\begin{tabular}{|c|c|c|c|c|c|c|c|c|}
\hline & \multicolumn{4}{|c|}{ Uniform grouping } & \multicolumn{4}{|c|}{ Automated grouping } \\
\hline NG & Floors & $\begin{array}{c}\text { Column } \\
\text { lenght } \\
(\mathrm{cm})\end{array}$ & $\begin{array}{c}\text { Beam } \\
\text { height } \\
(\mathrm{cm})\end{array}$ & $\begin{array}{l}\text { Total } \\
\text { cost } \\
\text { (US\$) }\end{array}$ & Floors & $\begin{array}{c}\text { Column } \\
\text { lenght } \\
(\mathrm{cm})\end{array}$ & $\begin{array}{c}\text { Beam } \\
\text { height } \\
(\mathrm{cm})\end{array}$ & $\begin{array}{l}\text { Total } \\
\text { cost } \\
\text { (US\$) }\end{array}$ \\
\hline 1 & $1-20$ & 105 & 85 & $53,425.58$ & $1-20$ & 105 & 85 & $53,425.58$ \\
\hline \multirow[t]{2}{*}{2} & $1-10$ & 105 & \multirow[t]{2}{*}{85} & \multirow[t]{2}{*}{$51,118.04$} & $1-18$ & 100 & \multirow[t]{2}{*}{85} & \multirow[t]{2}{*}{$47,360.30$} \\
\hline & $11-20$ & 85 & & & $19-20$ & 55 & & \\
\hline \multirow[t]{4}{*}{4} & $1-5$ & 105 & \multirow[t]{4}{*}{85} & \multirow[t]{4}{*}{$49,201.94$} & $1-16$ & 100 & \multirow[t]{4}{*}{85} & \multirow[t]{4}{*}{$46,142.51$} \\
\hline & $6-10$ & 105 & & & 17 & 75 & & \\
\hline & $11-15$ & 100 & & & $18-19$ & 75 & & \\
\hline & $16-20$ & 65 & & & 20 & 55 & & \\
\hline \multirow[t]{4}{*}{5} & $1-4$ & 105 & \multirow[t]{4}{*}{85} & \multirow[t]{4}{*}{$48,631.38$} & $1-14$ & 100 & \multirow[t]{4}{*}{85} & \multirow[t]{4}{*}{$45,939.52$} \\
\hline & $5-8$ & 105 & & & 16 & 85 & & \\
\hline & $9-12$ & 105 & & & 17 & 70 & & \\
\hline & $13-16$ & 90 & & & 18 & 70 & & \\
\hline
\end{tabular}




\begin{tabular}{|l|l|l|l|l|l|l|}
\hline & $17-20$ & 60 & & $19-20$ & 50 & \\
\hline
\end{tabular}

\subsection{Example 3}

The third example presented here consists of a 6-floor two-bay frame illustrated in Fig 11 and taken from Akin and Saka [40], who also used Harmony Search to perform the optimization. Other authors such as Rajeev and Krishnamoorthy [41], Camp and Pezeshk [42] and Govindaraj and Ramasamy [43] studied the same structure, with the adoption of Genetic Algorithms.

In the example, horizontal loads of $10 \mathrm{kN}$ and vertical loads of $30 \mathrm{kN} / \mathrm{m}$, as shown in Fig.1, were applied to all floors, and concrete C-20 and steel CA-50 were adopted. The unit costs of concrete, steel and formworks are $735 \mathrm{Rs} . / \mathrm{m} 3,7.1 \mathrm{Rs} . / \mathrm{kg}$ and $54 \mathrm{Rs} . / \mathrm{m} 2$, respectively.

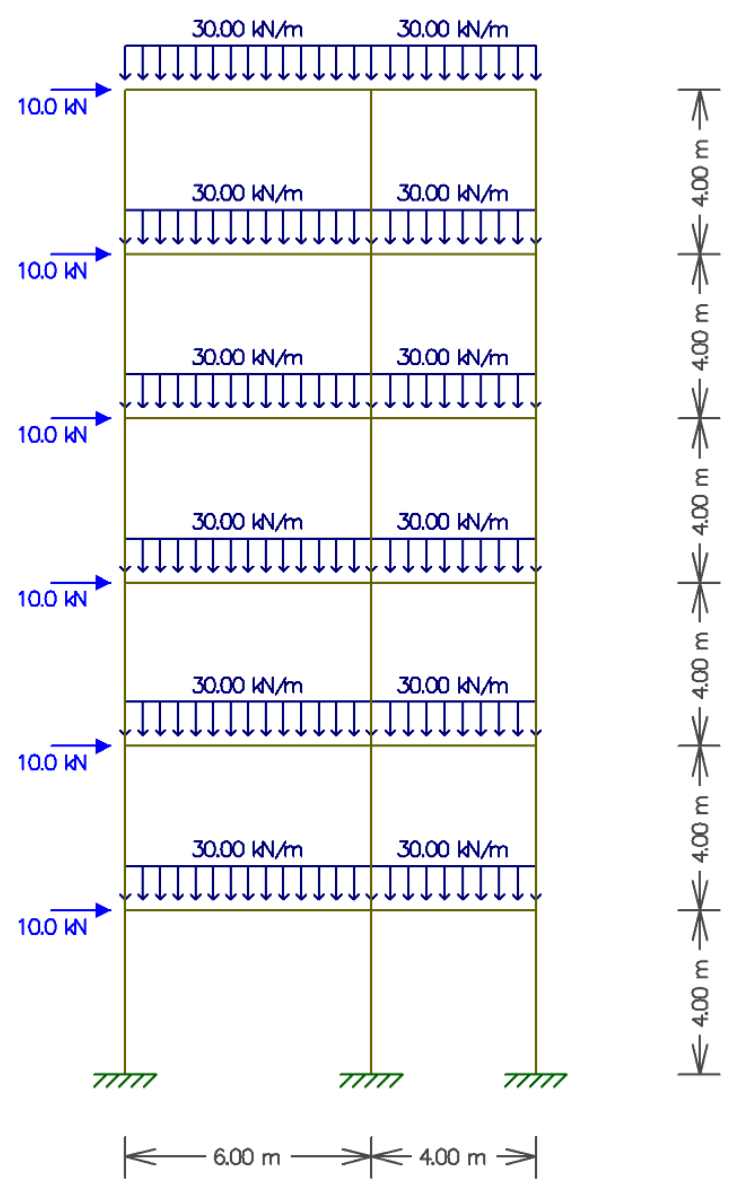

Figure 11 - Example 3: 6-floor building frame

Members are divided into three column groups and two beam groups. Columns in the same line are considered to belong to same group, and all beams constitute a unique group, with exception of roof beam.

At first, the structure was optimized according to the same grouping adopted by references [40] to [43]. The optimized structure presented a total cost of $25,386.27 \mathrm{Rs}$, while the results obtained by Rajeev and Krishnamoorthy [41], Camp and Pezeshk [42] and Govindaraj and Ramasamy [43] were, respectively: 26,052Rs., 24,959Rs., and 22,966Rs. These differences can 
be attributed to adopted codes and detailing issues. The optimum cost design obtained by Akin and Saka [40] was very high regarding the other studies, being 43,586.19Rs. It was attributed by the author mainly due to the inclusion of shear design constraints and requirements of special seismic moment frames.

In the sequence, the same structure was analyzed with different grouping schedules. A unique group was adopted to all beams, and the columns were divided in three groups according to floors, as in the previous examples. Figure 12 presents the optimized configuration obtained to automated grouping considering $\mathrm{NG}=3$ (19 design variables). It was observed almost the same optimized cost to uniform grouping $(22,775.67 \mathrm{Rs})$ and to automated grouping $(22,658.07 \mathrm{Rs})$. This small difference can be attributed to the reduced number of floors of the example.

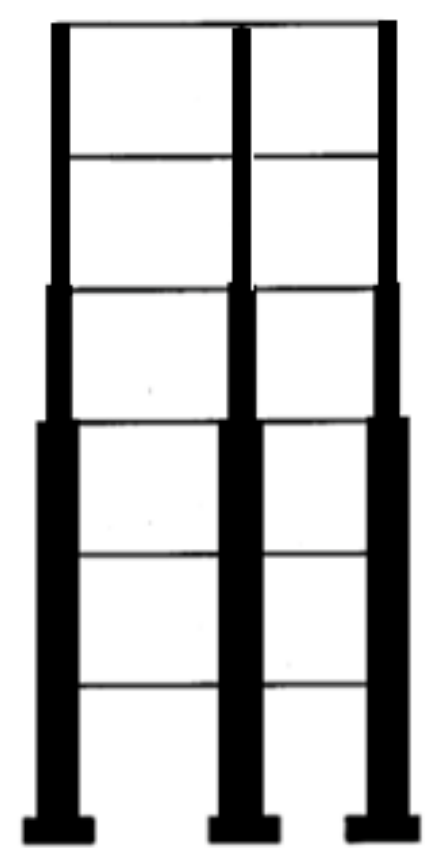

Figure 12 - Example 3: automated grouping to $\mathrm{NG}=3$

\section{CONCLUSIONS}

This paper presented the application of automated grouping of elements to the cost optimization of reinforced concrete plane frames, with sizing of beams and columns performed according to Brazilian standard ABNT/NBR 6118/14. For the optimization of the proposed problem, a variant of the Harmony Search algorithm was adopted. Unlike the usual procedure where, for a given configuration, just the dimensions of the elements are obtained, the proposed procedure includes the determination of the optimal grouping of columns as a variable aiming to obtain an additional economy. This is made by the usage of cardinality constraints, which defines the maximum number of different sections or characteristics allowed to a set of elements.

Aiming to verify the influence of automated grouping on the results, three examples adapted from the technical literature were presented, a 12-floor, a 20-floor and a 6-floor building plane frame. The structures of the examples were optimized to different numbers of groups, with and without the automated grouping. For the first structure, only vertical loads were considered, and the influence of the concrete strength was investigated. For the second example, a horizontal load is also considered. For both structures, a significant additional reduction in the total cost was observed when automated grouping is performed, even for a small number of groups, 
compared to uniform grouping of the columns. In the second example, which considered a bigger number of floors, the differences are more expressive, varying from 5.53 to $7.35 \%$. Finally, in the third example, a smaller structure was analyzed. In this case, a small difference was observed between the results with and without automated grouping. To all the examples, it was observed that to automated grouping a huge number of elements was allocated in the lowest group, with the remaining columns assuming small lengths.

The study of the influence of the concrete strength on the optimal results was also investigated, considering strength from 20 to $90 \mathrm{MPa}$. The best results were obtained for an intermediate resistance, with a cost reduction of $9.74 \%$ from the best $(40 \mathrm{MPa})$ to the worst case $(20 \mathrm{MPa})$. Previous studies indicated that, since for beams just part of the cross-section considers the concrete in resistance, a lower strength leads to higher costs [34], and an opposite behavior is observed for columns [35]. Due to this, in fact an intermediate strength should be expected when considering the whole frame.

In general, it can be concluded that a carefully grouping of columns can strongly affect the final cost of a structure. When applied in conjunction with the usual design variables, the proposed procedure can yield a significant additional economy. In addition, the strategy proposed in this paper reduces significantly the number of infeasible candidate solutions during the optimization process, aiming the obtention of better results with the same computational budget. This strategy, when associated to an efficient optimization method as in case of Modified Improved Harmony Search, can lead to good results with an acceptable computational time, since the number of variables is not increased significantly. This procedure can be implemented in optimization packages, and the general conclusions presented here can be adopted by designers in their current practice.

In spite of the fact that some simplifications were considered in the computational implementation of the formulation, they do not influence the results or the conclusions obtained, since they were adopted in all the structures analyzed.

\section{ACKNOWLEDGEMENTS}

The authors acknowledge the financial support of the Brazilian Council for Scientific and Technological Development - CNPq (Grant: 302736/2017-4) and of the Spanish Ministry of Economy and Competitiveness, along with FEDER funding (Project: BIA2017-85098-R).

\section{REFERENCES}

[1] Medeiros, G.F.; Kripka, M. Optimization of reinforced concrete columns according to different environmental impact assessment parameters. Engineering Structures, 2014, 59 : 185-194. http://dx.doi.org/10.1016/j.engstruct.2013.10.045.

[2] Yu, R.; Zhang, D.; Haichun, Y. Embodied energy and cost optimization of RC beam under blast load. Mathematical Problems in Engineering 2017. https://doi.org/10.1155/2017/1907972.

[3] Kaveh, A.; Sabzi, O. Optimal design of reinforced concrete frames using big bang-big crunch algorithm, International Journal of Civil Engineering, IUST, 2012, 3, 10: 189-200. ISSN: 2383-3874

[4] Payá, I.; Yepes, V.; González-Vidosa, F.; Hospitaler, A. Multiobjective optimization of concrete frames by simulated annealing. Computer-Aided Civil and Infrastructure Engineering. 2008; 23:596-610. https://doi.org/10.1111/j.1467-8667.2008.00561.x. 
[5] García-Segura, T.; Yepes, V. Multiobjective optimization of post-tensioned concrete boxgirder road bridges considering cost, $\mathrm{CO} 2$ emissions, and safety. Engineering Structures 2016, 125: 325-336. https://doi.org/10.1016/j.engstruct.2016.07.012.

[6] Martinez-Martin, F.J.; Gonzalez-Vidosa, F.; Hospitaler, A.; Yepes, V. Multi-objective optimization design of bridge piers with hybrid heuristic algorithms. Journal of Zhejiang University-SCIENCE A (Applied Physics \& Engineering), 2012, 13(6):420-432. https://doi.org/10.1631/jzus.A1100304.

[7] Yepes, V.; García-Segura, T.; Moreno-Jiménez, J.M. A cognitive approach for the multiobjective optimization of RC structural problems. Archives of Civil and Mechanical Engineering, 2015, 15(4):1024-1036. https://doi.org/10.1016/j.acme.2015.05.001.

[8] Kaveh, A., Ardalani, S. (2016) Cost and CO2 emission optimization of reinforced concrete frames using ECBO algorithm. Asian Journal of Civil Engineering, 2016, 17(6):831-858. https://doi.org/10.1007/978-3-319-48012-1_17

[9] Kripka, M.; Medeiros, G.F.; Lemonge, A.C.C. Use of optimization for automatic grouping of beam cross-section dimensions in reinforced concrete building structures. Engineering Structures, 2015, 99: 311-318. https://doi.org/10.1016/j.engstruct.2015.05.001.

[10] Brazilian Association of Technical Standards, Procedures for the design of reinforced concrete structures. NBR 6118, Rio de Janeiro, 2014 (in Portuguese). ISBN: 978-85-0704941-8

[11] Medeiros, G.F.; Kripka, M. Harmony Search algorithm applied to the optimization of reinforced concrete columns. In: 3rd International Conference on Engineering Optimization - EngOpt 2012, 2012, Rio de Janeiro. Proceedings of EngOpt 2012. ISBN 978-85-7650-344-6

[12] Molina-Moreno, F.; García-Segura, T.; Martí, J.V.; Yepes, V. Optimization of buttressed earth-retaining walls using hybrid Harmony Search algorithms. Engineering Structures, 2017, 134:205-216. https://doi.org/10.1016/j.engstruct.2016.12.042.

[13] García-Segura, T.; Yepes, V.; Alcalá, J.; Pérez-López, E. Hybrid harmony search for sustainable design of post-tensioned concrete box-girder pedestrian bridges. Engineering Structures, 2015, 92:112-122. https://doi.org/10.1016/j.engstruct.2015.03.015.

[14] Barbosa, H.J.C.; Lemonge, A.C.C. A genetic algorithm encoding for a class of cardinality constraints. In: GECCO 2005, Proceedings of the Genetic and Evolutionary Computation Conference. New York: ACM Press; 2005, 1193-200. ISBN: 1-59593-0108.

[15] Lemonge, A.C.C.; Barbosa, H.J.C.; da Fonseca, L.G.; Coutinho, A. ALGA - A genetic algorithm for topology optimization of dome structures. In: Proceedings of the 2nd International Conference on Engineering Optimization, EngOpt 2010. ISBN: 978-98996264-3-0.

[16] Herencia, J.E.; Haftka, R.T. Structural optimization with limited number of element properties. Structural and Multidisciplinary Optimization, 2010, 41(5):817-820. https://doi.org/10.1007/s00158-009-0457-2.

[17] Carvalho, J.P.G.; Lemonge, A.C.C.; Carvalho, E.C.R.; Hallak, P.H.; Bernardino, H.S. Truss optimization with multiple frequency constraints and automatic member grouping. Structural and Multidisciplinary Optimization. 2018, 57:547-577. https://doi.org/10.1007/s00158-017-1761-x. 
[18] Biedermann, J.D.; Grierson, D.E. A generic model for building design. Engineering with Computers, 1995 11(3):173-184. https://doi.org/10.1007/BF01271283.

[19] Lemonge, A.; Barbosa, H.; Coutinho, A.; Borges, C. Multiple cardinality constraints and automatic member grouping in the optimal design of steel framed structures. Engineering Structures, 2011, 33:433-444. https://doi.org/10.1016/j.engstruct.2010.10.026.

[20] Carvalho, J.P.G., Lemonge, A.C.C., Hallak, P.H., Vargas, D.E.C. A differential evolution to find the best material groupings in truss optimization. In: 6th International Conference on Engineering Optimization, 2018, pp. 01-12. ISBN: 978-3-319-97773-7

[21] Liu, X.; Cheng, G.; Wang, B.; Lin, S. Optimum design of pile foundation by automatic grouping genetic algorithms. International Scholarly Research Notices Civil Engineering, 2012. http://dx.doi.org/10.5402/2012/678329.

[22] Kripka, M.; Medeiros, G.F.; Lemonge, A.C.C. Structural optimization of reinforced concrete building grillages considering cardinality constraints. In: 10th World Congress on Structural and Multidisciplinary Optimization, 2013, pp. 01-06.

https://www.issmo.net/wcsmo10/Papers/5398.pdf (last access: 11/23/2018)

[23] Cohn, M.Z.; Dinovitzer, A.S. Application of structural optimization. ASCE Journal of Structural Engineering, 1994, 120(2): 617-649. https://doi.org/10.1061/(ASCE)07339445(1994)120:2(617).

[24] Camp, C.V.; Huq, F. CO2 and cost optimization of reinforced concrete frames using a big bang-big crunch algorithm. Engineering Structures, 2013, 48:363-

372. https://doi.org/10.1016/j.engstruct.2012.09.004.

[25] Sorensen, K.; Sevaux, M.; Glover, F. A history of metaheuristics. In ORBEL29-29th Belgian Conference on Operations Research, 2015. https://arxiv.org/pdf/1704.00853.pdf (last access: 11/23/2018)

[26] Fister Jr, I.; Mlakar, U.; Brest, I.; Fister, I. A new population-based nature-inspired algorithm every month: Is the current era coming to the end? In StuCoSReC - 3rd Student Computer Science Research Conference, 2016, Ljubljana. ISBN: 978-961-6984-37-9.

[27] Yoo, D.; Kim, J.; Geem, Z. Overview of Harmony Search algorithm and its applications in civil engineering. Evolutionary Intelligence, 2014, 7(1): 3-6.

https://doi.org/10.1007/s12065-013-0100-4.

[28] Geem, Z.W.; Kim, J.H.; Loganathan, G.V. A new heuristic optimization algorithm: Harmony Search. Simulation, 2001, 76(2): 60-68. https://doi.org/10.1177/003754970107600201.

[29] Yadav, A.; Yadav, N.; Kim, J.H. A Study of Harmony Search Algorithms: Exploration and Convergence Ability. J.H. Kim and Z.W. Geem (eds.), Harmony Search Algorithm, Advances in Intelligent Systems and Computing 382. Springer-Verlag Berlin Heidelberg, 2016. https://doi.org/10.1007/978-3-662-47926-1_6.

[30] Fourie, J.; Green, R.; Geem, Z.W. Generalised Adaptive Harmony Search: A comparative analysis of modern Harmony Search. Journal of Applied Mathematics, 2013, Article id 380985, 13 pages. http://dx.doi.org/10.1155/2013/380985.

[31] Ingram, G.; Zhang, T. Overview of applications and developments in the Harmony Search algorithm. In: Geem Z.W. Music-Inspired Harmony Search Algorithm, Springer, Sci191, pp. 15-37, 2009. https://doi.org/10.1007/978-3-642-00185-7_2. 
[32] Mahdavi, M.; Fesanghary, M.; Damangir, E. An improved harmony search algorithm for solving optimization problems. Applied Mathematics and Computation, 2007, 188: 15671579. https://doi.org/10.1016/j.amc.2006.11.033.

[33] Medeiros, G.F.; Kripka, M. Modified harmony search and its application to cost minimization of RC columns. Advances in Computational Design, 2017, 2: 1-13. https://doi.org/10.12989/acd.2017.2.1.001.

[34] Medeiros, G.F.; Kripka, M. Structural optimization and proposition of pre-sizing parameters for beams in reinforced concrete buildings. Computers and Concrete, 2013,11(3):1-18. https://doi.org/10.12989/cac.2013.11.3.253.

[35] Bordignon, R.; Kripka, M. Optimum design of reinforced concrete columns subjected to uniaxial flexural compression. Computers and Concrete, 2012, 9(5): 345-358. https://doi.org/10.12989/cac.2012.9.5.327.

[36] Kripka, M.; Boito, D.; Triches, J.; Medeiros, G.F. Optimization of reinforced concrete frames by Harmony Search method. In: 11th World Congress on Structural and Multidisciplinary Optimisation, 2015, Sydney, Australia. Proceedings of WCSMO-11. ISBN 13: 978-0-646-94394-7.

[37] Rahmanian, I.; Lucet, Y.; Tesfamariam, S. Optimal design of reinforced concrete beams: A review. Computers and Concrete, 2014, 13(4):457-482. http://dx.doi.org/10.12989/cac.2014.13.4.457

[38] Boito, D. Heuristic optimization of reinforced concrete plane frames. (M.Sc. Dissertation), University of Passo Fundo (in Portuguese), 2016. http://docs.upf.br/download/ppgeng/2016/2013-deise-boito.pdf (last access: 11/23/2018).

[39] Kaveh, A.; Zakian, P. Seismic design optimisation of RC moment frames and dual shear wall-frame structures via CSS algorithm. Asian Journal of Civil Engineering (Building and Housing), 2014, 15(3): 435-465. https://doi.org/10.1007/s42107-018-0088-2.

[40] Akin, A; Saka, M. P. Harmony search algorithm based optimum detailed design of reinforced concrete plane frames subject to ACI 318-05 provisions. Computers \& Structures, 2015, 147: 79-95. https://doi.org/10.1016/j.compstruc.2014.10.003.

[41] Rajeev, S.; Krishnamoorthy, C.S. Genetic algorithm-based methodology for design optimization of reinforced concrete frames, Computer-Aided Civil Infrastructral Engineering, 1998, 13(1): 63-74. https://doi.org/10.1111/0885-9507.00086.

[42] Camp, C.V.; Pezeshk, S.; Hansson, H. Flexural design of reinforced concrete frames using a genetic algorithm, The Journal of Structural Engineering ASCE, 2003, 129(1): 105-115. https://doi.org/10.1061/(ASCE)0733-9445(2003)129:1(105).

[43] Govindaraj, V.; Ramasamy, J.V. Optimum detailed design of reinforced concrete frames using genetic algorithms, Engineering Optimization, 2007, 39(4): 471-494. https://doi.org/10.1080/03052150601180767 